\title{
Clinical and humanistic impact of a minor ailment service in community pharmacy: a cluster randomised controlled trial.
}

\author{
Noelia Amador-Fernández ${ }^{1}$, Shalom Benrimoj², Antonio Olry de Labry Lima ${ }^{3}$, Victoria \\ Garcia-Cardenas $^{4}$, Miguel Angel Gastelurrutia ${ }^{5}$, Vicente J Baixauli-Fernández ${ }^{1}$, $\mathrm{M}^{\mathrm{a}}$ Teresa \\ Climent-Catalá $^{1}$, Vicente Colomer-Molina ${ }^{6}$, and Fernando Martinez Martinez ${ }^{5}$ \\ ${ }^{1}$ Spanish Society of Community Pharmacists \\ ${ }^{2}$ Universidad de Granada - Campus de Cartuja \\ ${ }^{3}$ Andalusian School of Public Health \\ ${ }^{4}$ University of Technology Sydney \\ ${ }^{5}$ University of Granada \\ ${ }^{6}$ Community pharmacy
}

November 9, 2020

\begin{abstract}
Abstract Aim To evaluate the clinical and humanistic patient outcomes of a community pharmacy (CP) Minor Ailment Service (MAS) compared to usual pharmacist care (UC). Methods A cluster randomised controlled trial was conducted over six months in CP. The pharmacist-patient intervention consisted of a standardised consultation on a web-based program using co-developed protocols pharmacists' training, practice change facilitators and patients' educational material. Patients were followed up ten days after initial consultation. Primary outcomes were appropriate medical referral and changes to direct product request. Secondary outcomes were symptom resolution, reconsultation rates for the same ailment and health related quality of life (HRQoL). Results A total of 808 patients were recruited by 27 CP (323 MAS and 485 UC). Patients visiting MAS pharmacies had higher odds for being referred to the general practitioner $(\mathrm{OR}=2.343$, CI95\% $=[1.146-4.792])$; a higher increase in HRQoL $(\mathrm{OR}=1.026, \mathrm{CI} 95 \%=[1.002-1.051])$ and higher number of reconsultation $(\mathrm{OR}=1.833, \mathrm{CI} 95 \%=[1.151-2.919])$ compared to UC. No significant differences were observed for symptom resolution and modification of treatments with direct product requests. Conclusions Patients with minor ailments are triaged and managed in a safe and effective way in CP, facilitating appropriate self-selection of non-prescription medicines. MAS reinforce pharmacists' involvement with patient engagement.
\end{abstract}

\section{Hosted file}

British Journal of Clinical Pharmacology_Manuscript.pdf available at https://authorea.com/ users/374370/articles/491896-clinical-and-humanistic-impact-of-a-minor-ailment-servicein-community-pharmacy-a-cluster-randomised-controlled-trial

\section{Hosted file}

British Journal of Clinical Pharmacology_Tables.pdf available at https://authorea.com/users/ 374370/articles/491896-clinical-and-humanistic-impact-of-a-minor-ailment-service-incommunity-pharmacy-a-cluster-randomised-controlled-trial 